\title{
Correction to: TDT-L0 a Test-Based Method for Assessing Students' Prior Knowledge in Engineering Graphic Courses
}

\author{
Barbara Motyl [D, Gabriele Baronio (10, Domenico Speranza (1), \\ and Stefano Filippi (1)
}

\section{Correction to:}

Chapter "TDT-L0 a Test-Based Method for Assessing Students' Prior Knowledge in Engineering Graphic Courses" in: F. Cavas-Martínez et al. (Eds.): Advances in Design Engineering, LNME, https://doi.org/10.1007/978-3-030-41200-5_50

The book was inadvertently published with an error in Chapter 50. The author's name has been changed from 'Barbara Moty' to 'Barbara Motyl'. 